\title{
The Hand Pronation Phenomenon: A Franco-German Tale
}

\author{
L. Tremolizzo ${ }^{a, b}$ R. Galbusera ${ }^{d}$ M.A. Riva ${ }^{c}$ G.C. Cesana ${ }^{c}$ I. Appollonio ${ }^{a, b}$ \\ C. Ferrarese $e^{a, b}$ \\ ${ }^{\text {a } D e p a r t m e n t ~ o f ~ N e u r o l o g y, ~ S . ~ G e r a r d o ~ H o s p i t a l, ~ M o n z a, ~ D e p a r t m e n t s ~ o f ~ b ~ N e u r o s c i e n c e ~ a n d ~ B i o m e d i c a l ~}$ \\ Technologies and ${ }^{\mathrm{C} C l i n i c a l}$ and Preventive Medicine, Research Centre on Public Health, University of \\ Milano-Bicocca, Milano, Italy; ${ }^{d}$ Department of Neurology, University Hospital Freiburg, Freiburg, Germany
}

Key Words

Strümpell $\cdot$ Gierlich $\cdot$ Babinski $\cdot$ Hand pronation $\cdot$ History

\begin{abstract}
The hand pronation phenomenon due to a pyramidal tract lesion is a sign commonly used for identifying a mild paresis, but the first descriptions of this maneuver seem to have been only partially investigated by the historians of neuroscience. Here we illustrate that this sign was most probably originally described by Adolf Strümpell (1853-1925) in 1901 and subsequently re-proposed by the illustrious French neurologist Joseph Babinski (1857-1932) in 1907, although with a slightly different focus of application. Finally, the Pronationsphaenomen was analyzed in detail in the subsequent work of Nikolaus Gierlich (1865-1944), a less-known German neurologist who tried one of the first detailed reports of the phylogenetic significance of this sign, publishing a paper in 1925. These works are reported here, detailing the existing discrepancies, along with notes on the relevant surrounding historical context. In particular, the undervalued contribution of Gierlich to the history of neuroscience and to the phylogenetic approach to semeiotics is analyzed in more detail and acknowledged.

Copyright $\odot 2011$ S. Karger AG, Basel
\end{abstract}

\section{The Hand Pronation Phenomenon}

Many patients who suffer a stroke commonly show a one-sided upper limb weakness, associated with a prevalent activity of pronator muscles; the supinators are indeed more severely impaired in the damage of the pyramidal pathway. In this situation, a pronation test can then be easily performed to reveal a slow inward rotation of the hand and forearm, due to the prevalence of pronator muscles. The patient, with closed eyes, usually outstretches his upper limbs horizontally, supinating his hands and extending elbows and fingers for a few seconds: the test is positive if the paretic hand and, later on, the limb slowly undergo an inward rotation (fig. 1a). This test may also be considered as positive if other positional changes happen, like abduction with a downward slow movement of the arm; so the unspecific term 'pronator drift' is often used to indicate this phenomenon [1]. In particular, it may be highly useful for identifying a mild paresis, which might be unrecognized during a routine

L.T. and R.G. contributed equally to the manuscript.

\section{KARGER}

Fax +41613061234 E-Mail karger@karger.ch www.karger.com
Lucio Tremolizzo, $\mathrm{MD}, \mathrm{PhD}$

University of Milano-Bicocca

Department of Neuroscience and Biomedical Technologies

Via Pergolesi 33, IT-20900 Monza (Italy)

Tel. +39 026448 8128, E-Mail lucio.tremolizzo@ unimib.it 
Fig. 1. The pronation test (a), as currently performed (positive test when in supine position, hand pronation can be observed), with respect to evocation of the pronation phenomenon (b), as described by Gierlich (positive test when reaching full hand supination is impossible). Photographs courtesy of Laura Melchionda.
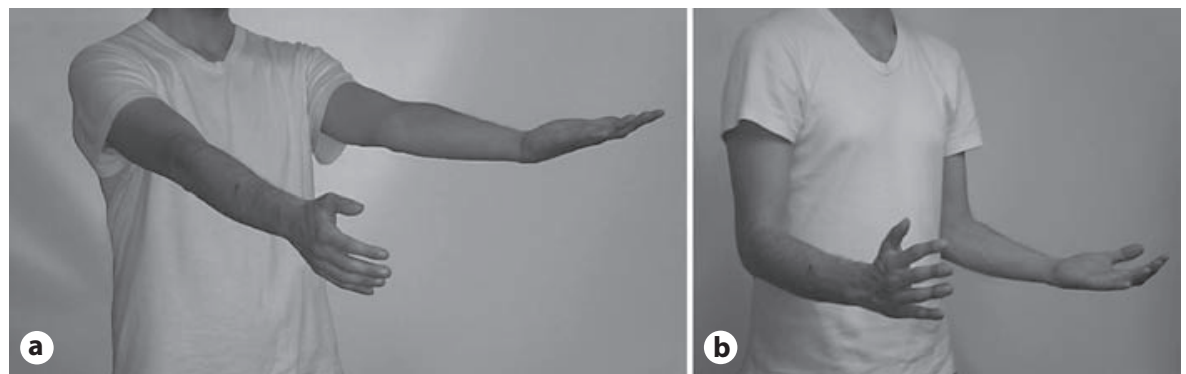

examination of muscle strength $[1,2]$. Interestingly, the debate on this test is still open, since Togay Işikay and Sener [3] recently suggested a modification in performing and interpreting it. These authors stated that vision could significantly affect the pronation test in patients who complained of a mild paresis, and resulted in having a sensory impairment confirmed by neurophysiologic tests. According to this new interpretation, an abnormal pronation test with open eyes would suggest a motor deficit, while an abnormal test with the eyes closed might indicate a sensory loss.

In this paper we went back to reconstruct the history of the hand pronation phenomenon, whose initial description was probably made in Germany and France at the beginning of the 20th century.

\section{Adolf Strümpell: From the Shinbone to the Hand}

Ernst Adolf Gustav Gottfried von Strümpell (18531925 ) is generally considered as one of the most important European pioneers of modern neurology and he is ranked among the founders of neurology as a clinical educational discipline in Germany. In sharp contrast to the opinion of his contemporaries (in particular Wilhelm Erb [1840-1912], his professor in Leipzig) Strümpell was among the first to consider neurology more closely related to psychiatry than to internal medicine [4]. In particular, he accurately investigated psychogenic influences on neurological symptoms, particularly 'post-accident neuroses', neurasthenia and hysteria [4]. Strümpell is also known for his description of the 'tibialis phenomenon' ('Tibialisphaenomen'), the dorsal flexion of the great toe and supination of the foot evoked by flexion of the knee on the pelvis [5]. This maneuver, well described in a 1901 paper, is nowadays referred to as 'Strümpell's sign' and indicates lesions of the pyramidal tract. In the same paper, reflecting on the ontogeny of the pyramidal tract, Strümpell described other 'muscular synergies' arising from the lack of inhibition due to lesions of this pathway. Among them, he proposed the term 'Pronationsphaenomen' indicating the pronation of the affected forearm when the hemiparetic patient outstretched his arms with the palms facing above. In 1914, Joseph Déjerine (18491917), in his 'Sémiologie des affections du système nerveux', subsequently named the same clinical sign 'Lephénomène de pronation de Strümpell' [6]. Strümpell himself, however, concluded stating that further studies were needed to completely understand this type of phenomenon and to elaborate its clinical significance. In particular, due to his interest in psychic diseases and their clinical diagnosis, he suggested the use of the pronation test in distinguishing hysteria from organic disorders.

\section{Joseph Babinski and the Differential Diagnosis of Hysteria}

At the beginning of the 20th century, the identification of new neurological diagnostic signs was felt as a major question in clinical research and the studies conducted by one of the most famous of Charcot's pupils, the French neurologist Joseph Babinski (1857-1932), were along this line. In particular, in 1907 Babinski wrote an abstract 'on the pronation of the hand in the organic hemiplegia' [7], where he described the phenomenon of active involuntary pronation of the paretic hand following its passive supination by the examiner. This finding was connected to an intensification of the pronator teres reflex; patients frequently developed a spastic pronation contracture typical of a lesion within the pyramidal tract. Finally the French neurologist concluded that this sign could help to distinguish organic from hysterical hemiplegia ('c'est là un signe qui peut aider à distinguer l'hémiplégie organique de l'hémiplégie hystérique') [7, 8]. Notably, at that time, hysteria and its differential diagnosis was heavily discussed in French academies and in the 'Société de Neurologie' [9]. Babin- 
ski dominated this debate due to his strong personality and theoretical and clinical ability, dismembering the 'theatrical' picture of hysteria left by Charcot's experiments through hypnosis. So, in the writings of Babinski belonging to the period 1901-1924, we can find several attempts to identify and distinguish hysteria, also through neurological semeiotics $[9,10]$. For instance, the classical Babinski's sign (toe extension) was claimed not to occur in cases of hysterical paralysis [11]. Another one of these signs identified by the French neurologist was just the hand pronation phenomenon, aimed as well at helping in the differential diagnosis of hysteric hemiplegia [12]. Interestingly, Déjerine in his previously cited 1914 neurological semeiotics book also described what he calls 'Babinski's automatic sign of pronation', in which the hands of the patient, initially held by the examiner so that the palms are facing each other, are tossed into the air. In the absence of strength deficits, the hands remain vertical, the palm facing inside; in contrast, on the paralyzed side, the hand pronates, the palm facing the ground [6]. Nonetheless, a few years later the same test was going to be described once again, albeit further explored, by a less illustrious German neurologist, starting from an exactly opposite point of view and moving towards other purposes.

\section{Nikolaus Gierlich and the Phylogenesis of Supination}

Josef Nikolaus Gierlich was a German neurologist (b. January 7th, 1865, Wipperfuehrt, d. October 17th, 1944, Wiesbaden). He studied Medicine and graduated in Strasbourg in 1891 with a thesis 'about secondary degeneration in infantile paralysis'. In administrative archives, he is mentioned in 1892/1893 as assistant physician at the hydrotherapic institute 'Nerothal' in Wiesbaden and then, from 1893/1894 on, as chief doctor at the same institution, then named 'Bad Nerothal' [13]. During his career, he wrote some monographs about neurological and psychiatric themes, among which a compilation of surveys 'about neurofibrils in the central nervous system' (1907) [14], a work 'about the symptomatology and differential diagnostic of posterior cranial cavity diseases' (1910) [15], 'studies in paranoia' (1908) [16], and a dissertation 'about nature, symptomatology and therapy of hemiplegic paralysis' (1913) [17]. The forearm pronation phenomenon was described by Gierlich in a paper dated 1925 [18]. Here, the German neurologist stated that it could be observed by asking the patient to place his arm along the trunk, extending hand and forearm at a rightangle. Gierlich's sign basically consisted of a mild contracture of the forearm pronator muscles of the afflicted side, so that an outward rotation of the forearm was severely impaired and the hand, in the attempt to supinate, reached at the most an intermediate position between a full supination and a full pronation (fig. 1b). The pronation phenomenon (Pronationsphaenomen), defined by Gierlich as 'extremely easy to evoke', was observed by this author in over 800 patients. He discussed his clinical experience in 12 patients who suffered a stroke and proposed the forearm pronation as an early indicator of damage of the pyramidal pathways. In particular, in Gierlich's opinion, this clinical sign should be seen as the equivalent of the most famous Babinski sign (toe extension following plantar stimulation) for the upper limb. In particular, Gierlich knew the classical Babinski sign very well and was very interested in its pathology, as evidenced by his paper, written in the year before, on 'the pathogenesis of the phenomenon of Babinski and its correlation with the escape reflex of the human spinal cord' [19].

The study on the pathogenesis of the pronation phenomenon led Gierlich to examine its presence among infants based on the model of Babinski, who in his first elaborate article about the 'phénomène des orteils' had argued that the evocation of the reflex in the newborn, with the pyramidal system not yet fully developed, was the confirmation that this sign was related to a disturbance in the function of the pyramidal tract [20]. Likewise, in his paper Gierlich reported his own observation of the upper limbs of infants in a neonatal ward, drawing the same conclusion as Babinski: the presence of the pronation phenomenon in the hand in newborns confirmed its potential use in the evaluation of the damage of the pyramidal pathways. These observations in the newborn led the German neurologist to include in the last part of his paper some remarks about the phylogenesis of the supination movements. These considerations were likely influenced by the 'biogenetic law' of Ernst Haeckel (18341919) that 'ontogeny is nothing other than a short recapitulation of phylogeny' [21], as shown by Gierlich's statement that ontogeny is 'a quick phylogenesis' (verkuerzte Phylogenese) [18]. So, he argued that the pronation, associated with flexure and abduction movements, represents the most important movement in amphibians, fish and reptiles, necessary to set the water back and to move forward, and that it is still strongly present in mammals. He then asserted that a complete supination is possible only among the most evolved animals, so that the palm of the hand can be completely turned upwards; the 
second part of the outward rotation movement appears then to be related to the formation and development of the pyramidal pathways. Thus, Gierlich made some teleological speculations, arguing how the development of the anatomy of the upper limb was aimed at the rotation of the hand. Indeed, in his opinion, a hypothetical explanation for the development of supination could be found in the necessity of primitive men to defend themselves, to raise and to hit with a stick, to stab fierce beasts or just to sell a stone [18]. The full supination of the hand would therefore constitute a recent evolutionary conquest, associated with the development of the cerebral cortex. Nevertheless, this movement proves to be relatively weak and, in the event of an impairment of the pyramidal system, it results more severely involved; thus, the pronation movements, generated by phylogenetically older subcortical centers return to prevail. This idea somehow echoes the theories exposed a few years earlier by John Hughlings Jackson (1835-1911). In fact, in his celebrated 1884 Croonian lecture, the British neurologist proposed that phylogenetically younger structures such as the pyramidal tract, when compared to other 'older' motor control systems, could be more affected by pathological processes, denominating his theory 'evolution-dissolution' [22].

However, the paper on the Pronationsphaenomen is not the only one written by Gierlich on the phylogenesis of motor impairment. Five years later, he wrote an article on the relationship between the type of preference of hemiplegic paralysis and the phylogenetic development of the pyramidal pathways [23]. Moreover, in 1933, he published a work on the phylogenetic impact of the epileptic seizure, trying to provide an evolutionary theory on the origins of the epilepsy [24]. Nowadays, conceivably, Gierlich's ideas regarding the explication of the human movement and neurological diseases through phylogenesis might appear obscure and not completely acceptable by modern scientists. However, it is worth remembering that, as stated by van Gijn, during the first half of the 20th century 'guesswork about the purpose of reflexes was more respectable than it is today, although these speculations were often veiled under terms like physiological significance' [25].

\section{Conclusions: Neurological Semiotics Evolution (and Dissolution?)}

Either completely stretching or not stretching arms and even with the other small differences in performing this neurological maneuver, both involuntary pronator drift and lack of voluntary supination seem to give us the same information regarding mild paresis due to upper motor neuron dysfunction. This is not surprising since neurological semeiotics has often been shaped by the contribution of various authors, sometimes strongly characterizing the specific neurological school of a country. As an example, in the attempt of testing the reliability of the hand pronation phenomenon, in 1952 Savitsky and Madonick shortly tracked down the history of this sign, denominating it after the 1929 description made by the USborn British neurologist Samuel Alexander Kinnier Wilson (1878-1937) [26]. As a matter of fact, in his famous book Wilson referred to the pronator sign as one of the 'little signs' of chorea, describing an outward rotation of the forearm when the patient extends his arms above the head, 'revealing an involuntary over-pronation of the elbow', so revealing an alternate, albeit different, method for evocating this phenomenon [27].

Going back again in time, surely German and French scholars have influenced each other over the years. In fact, at the end of the 19th century, some of the most illustrious German neuropsychiatrists (e.g. Wilhelm Erb, Adolph Strümpell and Sigmund Freud [1856-1939]) came into contact with Charcot and his pupils, acknowledging their importance in the development of the discipline [28]. However, at the same time the competition and the rivalry between these two countries due to political and economic reasons had sometimes influenced the mutual acknowledgments between French and German scientists, as well evidenced by the cases of Louis Pasteur (1822-1895) and Robert Koch (1843-1910) [29]. In his paper, Gierlich never referred to the first descriptions of the sign made by the German or the French colleague but we may suspect that he knew about it, considering, for example, both his knowledge of Babinski's previous works and the fact that he called this sign 'Pronationsphaenomen' (the same name used by Strümpell), even though in his paper he more clearly described an actual lack of supination. Therefore, the absence of any reference to previous works, particularly Babinski's, may be motivated by the political climate and the France-Germany relations after World War I.

Actually, as recognized by Strümpell himself, his description of the pronation phenomenon is very short as is that of Babinski and both mainly aimed at distinguishing organic from hysteric hemiplegia. On the other hand, in Gierlich's paper this sign, plausibly for the first time, was seriously considered as a useful tool for the evaluation of the damage of the pyramidal pathways. So despite the considerations about the first description and the French 
or German 'paternity' of the pronation phenomenon, Gierlich's work surely deserves closer attention from the scholars dedicated to the history of neuroscience, considering the important conceptual inputs he gave to the field.

\section{Acknowledgements}

We wish to thank Prof. Axel Karenberg, University of Cologne, for his useful advice and Mr. Jochen Dollwet, Wiesbaden Stadtarchiv, for supplying useful information.

\section{References}

-1 Anderson NE, Mason DF, Fink JN, Bergin PS, Charleston AJ, Gamble GD: Detection of focal cerebral hemisphere lesions using the neurological examination. J Neurol Neurosurg Psychiatry 2005;76:545-549.

2 DeJong RN: Associated movements; in Haerer AF (ed): DeJong's The Neurologic Examination, ed 6. Philadelphia, Lippincott Williams \& Wilkins, 2005.

3 Togay Işikay C, Sener HO: Pronation test: eyes closed or open? Eur Neurol 2007;58:6569.

4 Erbguth FJ, Neundörfer B: Adolf Strümpell (1853-1925). J Neurol 2000;247:575-576.

5 Strumpell A: Über das Tibialisphanomen und verwandte Muskelsynergien bei spastischer Paresen. Dtsch Z Nervenh 1901;20: 436-444.

6 Déjerine J: Sémiologie des affections du système nerveux. Paris, Masson, 1914, p 260.

7 Babinski J: De la pronation de la main dans l'hémiplégie organique. Rev Neurol 1907;15: 755.

8 Kakitani FT, Collares D, Kurozawa AY, Lima PM, Teive HA: How many Babinski's signs are there? Arq Neuropsiquiatr 2010;68:662665.

9 Walshe F: Diagnosis of hysteria. Br Med J 1965;ii:1451-1454.

10 Laplane D, Bonduelle M: The debate over 'hysteria' (in French). Rev Neurol (Paris) 1999; 155:815-821.
11 Okun MS, Koehler PJ: Babinski’s clinical differentiation of organic paralysis from hysterical paralysis: effect on US neurology. Arch Neurol 2004;61:778-783.

12 Koehler PJ: The Barré and Mingazzini tests; in Koehler PJ, Bruyn GW, Pearce JMS (eds): Neurological Eponyms. New York, Oxford University Press, 2000, p 125.

13 Stadtarchiv, Im Rad 42, 65197 Wiesbaden, Germany.

14 Herxheimer G, Nikolaus G: Studien über die Neurofibrillen im Zentralnervensystem: Entwickelung und normales Verhalten, Veränderungen unter pathologischen Bedingungen. Wiesbaden, Bergmann, 1907.

15 Gierlich N: Symptomatologie und Differentialdiagnose der Erkrankungen in der hinteren Schädelgrube mit besonderer Berücksichtigung der für einen chirurgischen Eingriff zugängigen. Halle, Marhold, 1910.

16 Jelliffe SE, Gierlich N, Friedmann M: Studies in Paranoia. New York, J Nerv Ment Dis Publ Co, 1908.

17 Gierlich N: Über Symptomatologie, Wesen, und Therapie der Hemiplegischen Lähmung. Mit besonderer Berücksichtigung der Entwickelung und Funktion der Bewegungszentren in der Wirbeltierreihe. Wiesbaden, Bergmann, 1913.

18 Gierlich N: Über das Pronationsphaenomen der Hand usw. Z Nervenheilk 1925;84:69_ 85.

19 Gierlich N: Über die Pathogenese des Babinskischen Phänomens und seine Beziehung zum Fluchtreflex des menschlichen Rückenmarks. Z Ges Neurol Psychiatr 1924; 92:661-664.
20 Babinski J: Du phénomène des orteils et de sa valeur sémiologique. Semin Méd 1898;18: 321-322.

21 Richards RJ: The Tragic Sense of Life. Ernst Haeckel and the Struggle Over Evolutionary Thought. London, University of Chicago Press, 2008.

22 Jackson HJ: The Croonian Lectures on Evolution and Dissolution of the Nervous System. Br Med J 1884;1:703-707.

23 Gierlich N: Über die Beziehungen des Prädilektionstyps der hemiplegischen Lähmung zur phylogenetischen Entwicklung der Pyramidenbahnen. Z Ges Neurol Psychiatr 1920;60:59-76.

24 Gierlich N: Über die Bedeutung des phylogenetischen Einschlags im epileptischen Anfall. J Neurol 1933;130:111-116.

25 Van Gijn J: The Babinski Sign: A Centenary. Utrecht, Universiteit Utrecht, 1996.

26 Savitsky N, Madonick JM: Statistical control studies in neurology. II. The pronator sign of Wilson. AMA Arch Neurol Psychiatry 1952; 67:344-347.

27 Wilson SAK: Modern Problems in Neurology. New York, William Wood, 1929, p 218.

28 Lehmann HC, Hartung HP, Kieseier BC: Jean-Martin Charcot in German neurology (in German). Nervenarzt 2004;75:187-192.

29 Friedland GW, Friedman M: Medicine's 10 Greatest Discoveries. New Haven, Yale University Press Edition, 1998. 